\title{
2D:4D digit ratio is associated with cognitive decline but not frailty in community-dwelling older adults
}

\author{
Celina Gonçalves ${ }^{1,2}$ | Tiago Coelho $^{1}$ | Sérgio Machado ${ }^{3}$ | Nuno Barbosa Rocha1
}

\author{
${ }^{1}$ Laboratório de Reabilitação Psicossocial, \\ Escola Superior de Saúde do Instituto \\ Politécnico do Porto e Faculdade de \\ Psicologia e Ciências da Educação da \\ Universidade do Porto, Porto, Portugal \\ ${ }^{2}$ Departamento de Ciências do Desporto, \\ Instituto Politécnico de Bragança, \\ Bragança, Portugal \\ ${ }^{3}$ Laboratory of Panic and Respiration \\ (LABPR), Institute of Psychiatry (IPUB) \\ Federal University of Rio de Janeiro \\ (UFRJ), Rio de Janeiro, Brazil

\section{Correspondence} \\ Dr. Nuno Barbosa Rocha, Escola \\ Superior de Saúde, Instituto Politécnico \\ do Porto, Rua Dr. António Bernardino de \\ Almeida, 400, 4200-072 Porto, Portugal. \\ Email: nrocha@ess.ipp.pt
}

\begin{abstract}
Objectives: To understand the relation between 2D:4D ratio, frailty, and cognitive decline in community-dwelling elderly people.

Methods: A total of 175 community-dwelling elderly people were included. To determine frailty, participants completed the Tilburg Frailty Indicator (TFI) and the Survey of Health, Ageing and Retirement in Europe (SHARE-FI). Cognitive functioning was determined using the Mini-Mental State Examination (MMSE). 2D and 4D finger lengths of each hand were measured using a scanner. Barthel Index, Lawton, and Brody scale were also completed for each participant to determine the level of daily living functioning.

Results: We did not find any correlations between 2D:4D ratio and frailty measures. We found a significant correlation between 2D:4D ratio and MMSE scores in the women sampled.

Conclusions: We cannot ascertain any contribution of prenatal exposure to androgens to the frailty status of community-dwelling elderly people. We found that reduced prenatal exposure to testosterone in women may contribute to the prevention of cognitive decline in elderly women.
\end{abstract}

\section{1 | INTRODUCTION}

It is recognized that frailty increases with age (Ahmed, Mandel, \& Fain, 2007), while cognitive function declines (Guerrero-Berroa et al., 2009). Frail elderly become vulnerable due to health problems, isolation, poor quality of life and dependence, which easily lead to the need for preventive geriatric interventions, long-term care, hospitalization, and death (Fried et al., 2001; Lahousse, Maes, Ziere, \& Loth, 2014). Cognitive deterioration contributes to long-term functional impairments and reduced quality of life (Lawson et al., 1969). There are several factors that contribute to frailty and cognitive decline in older people. The concept of frailty must be a multidimensional concept that includes physical, psychological, and social variables (Andreasen, Sørensen, Gobbens, Lund, \& Aadahl, 2014; Gobbens \& Assen, 2014; Gobbens, Luijkx, Wijnen-Sponselee, \& Schols, 2010a, Gobbens et al., 2010b).

In older adults, low testosterone levels are associated with loss of muscle mass and strength, due to decreased protein synthesis (Feldman et al., 2002; Halil et al., 2013; Sakuma, \& Yamaguchi, 2012). There is also evidence that cognitive function could be influenced by testosterone levels (Barrett-Connor, Goodman-Gruen, \& Patay, 1999; Moffat et al., 2002). Low testosterone levels in older men appear to be associated with cognitive decline and risk of dementia (Wahjoepramono et al., 2016). However, there is conflicting evidence showing that cognitive function does not suffer any interference from testosterone intake (Huang et al., 2016).

The 2D:4D ratio is usually used as an indicator of prenatal testosterone exposure (Fink, Manning, \& Neave, 2006; Fink, Thanzami, Seydel, \& Manning, 2006) and is a fairly stable one (Anders, 2007; McIntyre, Cohn, \& Ellison, 2006). Low 2D:4D ratio reflects high testosterone exposure (Fink, Manning, \& Neave, 2006; Fink, Thanzami, Seydel, \& Manning, 2006). While there are some studies about the role of testosterone on frailty (Srinivas-Shankar \& Wu, 2009) and cognitive decline (Moffat, 2005) in older adults, only a few analyzed the impact of prenatal testosterone exposure (Halil 
et al., 2013). The aim of this study was to understand the relation between 2D:4D ratio, frailty, and cognitive decline in community-dwelling elderly people.

\section{2 | METHOD}

\section{1 | Sample/participants}

The sample was composed by 175 community-dwelling elderly people (aged more than 65 years). These were recruited from direct contact by the research team and from advertisements. We excluded participants with severe cognitive deterioration determined by the Mini Mental State Evaluation (score less than 10) and with severe medical conditions.

\section{2 | Instruments}

Several instruments were used in this study:

Tilburg Frailty Indicator (TFI) is a brief self-report survey for measuring frailty in older people (Coelho, Santos, Paúl, Gobbens, \& Fernandes, 2014; Gobbens et al., 2010a,b). The TFI is divided into two main sections: the first is composed of 10 questions ( 6 demographic and 4 focused on the determinants of frailty); the second comprises 25 questions divided into 3 components -8 items for the physical component, 4 items for the psychological component and 3 items for the social component. All items are rated dichotomously $(0-1)$, with higher scores representing higher frailty. Scores for each frailty component and a total frailty score $(0-15)$ are produced.

Survey of Health, Ageing and Retirement in Europe (SHARE-FI) (Santos-Eggimann, Cuénoud, Spagnoli, \& Junod, 2009) was based on five frailty items: exhaustion in the last month (yes/no); loss of appetite (loss/without alteration/increase); difficulty walking $100 \mathrm{~m}$ and steps (yes/no); engagement in activities that require a low or moderate energy level (less than once a week, once a week, between one and three times a month, never); and weakness measured by the grip strength of both hands with a dynamometer. Two consecutive measurements were taken and the analyses were conducted on averages of two readings for each hand.

Mini-Mental State Examination (MMSE) is a screening test for cognitive decline (Folstein, Folstein, \& McHugh, 1975). The MMSE is divided into six main parts: orientation (10 items); retention ( 2 exercises); attention and calculation ( 1 exercise); recent memory ( 1 exercise); and, language (7 exercises). The MMSE has a score range of 0-30. Potential participants with an MMSE $\leq 10$ did not enter the study.

Barthel Index is a scale that attempts to assess the participants' functional ability to perform basic activities of daily life
independently-Daily Life Basic Activities (DLBA)(Mahoney, \& Barthel, 1965) with 10 questions: personal hygiene, bathing, dressing, eating, mobility (walk), mobility (stairs), mobility (bed/chair), intestinal elimination, bladder function, and use of the toilet. This scale has a score range of 0-20.

Lawton and Brody scale seeks to evaluate the participants' functional ability to perform instrumental activities of daily life-Instrumental Activities of Daily Living (IADL) (Lawton et al., 1969) with eight questions: preparing meals, doing housework, washing, handling money, using the telephone, taking medications, shopping, and use of transportation. This scale has a score range of $0-23$, in that 23 is full independence.

Finally, we scanned each participant's hands using a highresolution scanner. The $2 \mathrm{D}$ and $4 \mathrm{D}$ fingers for each hand were measured (in $\mathrm{mm}$ ) from the middle of the basal crease to the edge of the fingertip using an Autometric Program that can easily and accurately measure 2D:4D ratios (Halil et al., 2013). The procedure was undertaken by two researchers for each hand and consensus was obtained for each measurement. The reliability of the two measurements for the right and left hand was high (ICC right hand: 0.93; ICC left hand: 0.92).

\section{3 | Procedures}

Each participant was contacted at their own home or daycare facility. The purpose of the study was explained and participants signed informed consent according to the Declaration of Helsinki of the World Medical Association. This study was reviewed and approved by the ethics committee of the Escola Superior de Saúde do Instituto Politécnico do Porto. Statistical analyses were conducted using software SPSS Statistics (v.23.0, SPSS Inc., IL) and was based on Pearson correlations between the 2D:4D ratio and frailty and cognitive scores. Multiple linear regression was also used to control for the influence of age on the relationship between 2D:4D ratios and the independent variable.

\section{3 | RESULTS}

A total of 175 older adults entered into this study. Descriptive statistics of the total sample and for men and women separately are presented in Table 1 .

There was no significant correlation between 2D:4D ratios and values of TFI or SHARE-FI in the total sample or separately in the men and women sampled. However, there was a trend toward significance regarding the physical dimension of the TFI $(r=.147 ; P=.052)$.

Surprisingly, for the total sample, there were significant correlations between MMSE, right hand 2D:4D $(r=.164$, 
TABLE 1 Descriptive statistics of the sample

\begin{tabular}{|c|c|c|c|c|c|c|}
\hline & \multicolumn{2}{|c|}{ Total sample $(n=175)$} & \multicolumn{2}{|c|}{ Men $(n=54)$} & \multicolumn{2}{|c|}{ Women $(n=121)$} \\
\hline & Mean & SD & Mean & SD & Mean & SD \\
\hline Age & 75.730 & 7.699 & 75.440 & 7.327 & 75.850 & 7.886 \\
\hline School education $(0-12)$ & 3.660 & 2.291 & 4.350 & 2.300 & 3.350 & 2.228 \\
\hline Weight $(\mathrm{kg})$ & 72.228 & 12.502 & 76.240 & 10.599 & 70.438 & 12.906 \\
\hline Height $(\mathrm{cm})$ & 162.765 & 6.976 & 167.703 & 6.694 & 160.562 & 5.908 \\
\hline DLBA & 18.525 & 3.130 & 18.851 & 3.194 & 18.380 & 3.104 \\
\hline IADL & 16.325 & 7.015 & 15.833 & 5.859 & 16.545 & 7.486 \\
\hline Mean 2D:4D & 0.961 & 0.033 & 0.957 & 0.032 & 0.962 & 0.033 \\
\hline Right hand 2D:4D & 0.952 & 0.038 & 0.945 & 0.031 & 0.955 & 0.041 \\
\hline Left hand 2D:4D & 0.967 & 0.036 & 0.964 & 0.038 & 0.968 & 0.036 \\
\hline Dr-1 & -0.014 & 0.037 & -0.019 & 0.034 & -0.012 & 0.038 \\
\hline
\end{tabular}

DLBA: Daily Life Basic Activities (Barthel Index); IADL: Instrumental Activities of Daily Living (Lawton and Brody Scale).

$P=.030)$ and left hand 2D:4D $(r=.185, P=.014)$. However, this outcome seems to have occurred due to the significance of the women's results; the men's results alone showed no significant correlation. Specifically, in women, the correlation between MMSE and 2D:4D in the right hand is significant $(r=.227 ; P=.012)$ and the same happens in the left hand $(r=.263 ; P=.004)$ (Table 2).

We also controlled for the effect of age on the MMSE score by regressing age and the 2D:4D variables on the independent variable (MMSE score). For the total sample and the right hand 2D:4D, the model was significant and explained $14.0 \%$ of the variance. Age was a significant predictor ( $\beta=-.339 ; P=.000)$ and the right hand $2 \mathrm{D}: 4 \mathrm{D}$ achieved a trend toward significance $(\beta=.124 ; P=.083)$. For the left hand, age was a significant predictor $(\beta=-.341 ; P=.000)$ and 2D:4D was significant $(\beta=.156 ; P=.028)$ in a model that explained $14.9 \%$ of the variance. For the female sample and for the right hand, the total model explained $18.4 \%$ of the variance. Age was a significant predictor $(\beta=-.370$; $P=.000)$ and the 2D:4D ratio showed a trend toward significance $(\beta=.158 ; P=.064)$. For the left hand, the total model explained $19.8 \%$ of the variance. Age was a significant predictor $(\beta=-.365 ; P=.000)$ as well as the $2 \mathrm{D}: 4 \mathrm{D}$ ratio $(\beta=-.199 ; P=.019)$.

\section{4 | DISCUSSION}

In this study, we found that $2 \mathrm{D}: 4 \mathrm{D}$ ratios were in general higher in women than in men. These results were consistent with previous studies that found a higher 2D:4D ratio in women than in men (Adam et al., 2013; Malas, Dogan, Hilal Evcil, \& Desdicioglu, 2006).

Contrary to what was expected, we found that the ratio 2D:4D was not significantly correlated with frailty or any of its components. However, there was a trend toward significance regarding the physical components of frailty, which is in accordance with the fact that testosterone is an anabolic hormone that influences protein synthesis and is thought to provide protection from the development of sarcopenia. Accordingly, there is evidence associating the 2D:4D ratio with strength tests ((Fink, Manning, \& Neave, 2006; Fink, Thanzami, Seydel, \& Manning, 2006; Halil et al., 2013), which was not replicated in a female sample (Anders, 2007).

One interesting result from our study is that MMSE values showed significant correlations with the 2D:4D ratio in the female sample, suggesting that lower prenatal exposure to testosterone is associated with lower cognitive decline. With regard to the male sample, there were no significant correlations. There are no definite explanations for these findings. It is generally recognized that lower total and free testosterone levels are associated with poorer cognitive function in middle-aged and older men (Yeap, 2009). However, cross-sectional data shows that MMSE has weak correlations with free testosterone and no correlations with total testosterone in older men (Yeap et al., 2008). In women, current evidence is far from establishing an association between prenatal exposure to androgens and cognitive function (Austin, Manning, Mcinroy, \& Mathews, 2002; Coolican \& Peters, 2003; Poulin, O’ Connell, \& Freeman, 2004). Associations with current levels of testosterone among women is also conflicting, with studies showing positive, negative and absence of correlations. 


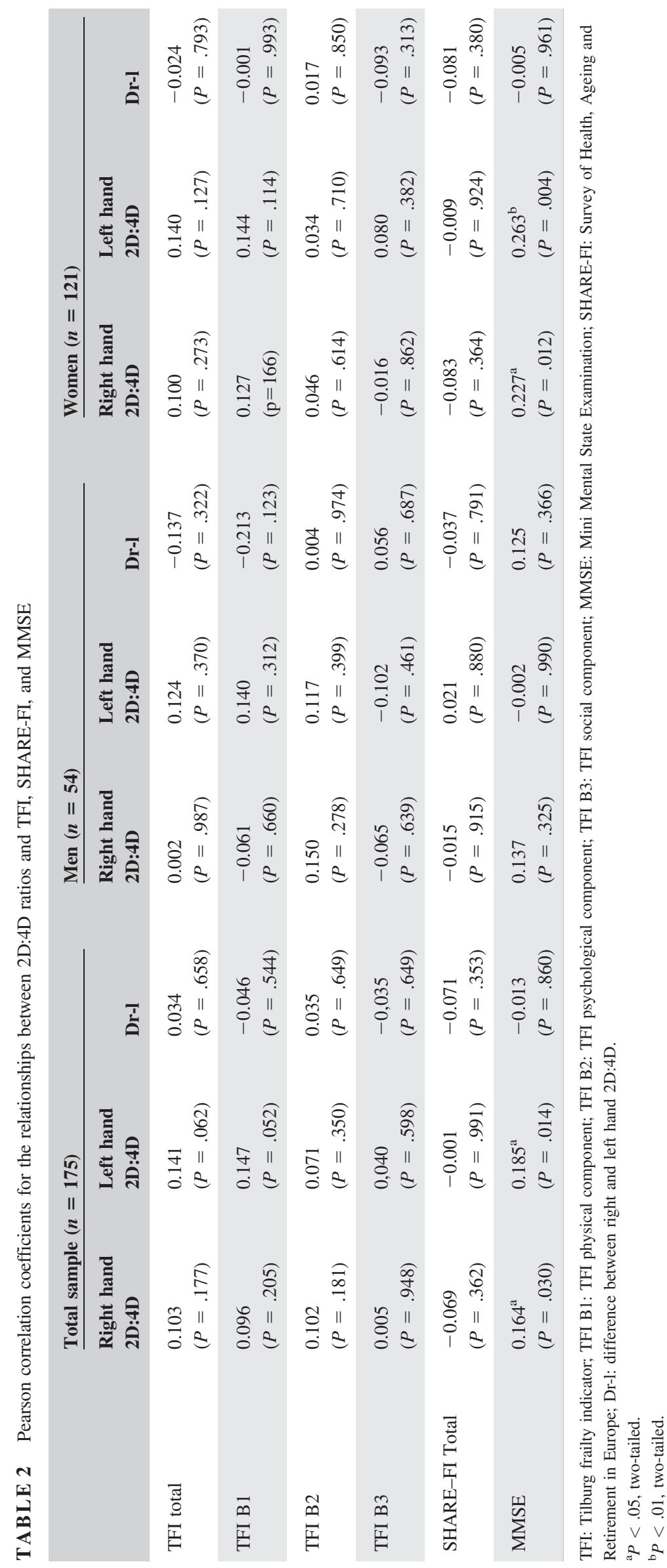


While 2D:4D is a fixed and predetermined variable, there are a myriad of other processes that occur during the lifespan that may have an impact on cognition (Baumgart et al., 2015). First, we should note that there is no linear association between prenatal exposure to androgens and actuals levels of testosterone in adults (Manning, Scutt, Wilson, \& LewisJones, 1998; Neave, Laing, Fink, \& Manning, 2003). Furthermore, there are differences in the pattern of testosterone decline over the years (Ellison et al., 2002). It is possible that women with increased precocious androgens exposure may suffer from a steeper decline in testosterone in later years, resulting in increased cognitive deterioration. However, only longitudinal data may confirm this hypothesis.

Also, it has been hypothesized that early exposure to testosterone has a role in personality and in the decisions that people make about their lifestyle. For example, there is evidence showing that openness to experience is significantly associated with more female-typical 2D:4D (Burton, Guterman, \& Baum, 2013) and even experience seeking (a dimension of sensation seeking), which initially was hypothesized to be associated with smaller 2D:4D ratios based on theory, appears to be associated with more female-like 2D:4D ratios (Voracek, Tran, \& Dressler, 2010). Based on our findings, we hypothesize that exposure to lower levels of testosterone in utero may predispose people to engage in more cognitively oriented activities during their daily life (e.g., reading, writing, engaging in conversations, studying, going to libraries and museums), which can protect them from cognitive deterioration in the long term. Of course, drawing any conclusions based on the association between the 2D:4D finger length ratio and personality traits should be made with extreme caution, given that current data is largely inconsistent (Lippa, 2006).

There are some limitations to this study, including the wide age range, without enough stratification across age groups and without a homogenous proportion of frail older adults across age groups. Also, finger length was measured indirectly using a scanner. This method of 2D:4D measurement tends to result in lower values than when $2 \mathrm{D}: 4 \mathrm{D}$ is measured directly from the fingers. This effect is most exaggerated in males compared to females (see Ribeiro, Neave, Morais, \& Manning, 2016, for a review).

\section{CONCLUSION}

The aim of the study was to understand the relationship between 2D:4D ratio, frailty and cognitive decline in the elderly population. The results suggested that there is no relationship between 2D:4D (indicator of testosterone) and multidimensional frailty in elderly people. Moreover, the present study contributes to the existing literature by showing the association between 2D:4D ratio and MMSE values in elderly women, suggesting a role of fetal sex steroids in cognition over the lifespan.

\section{ACKNOWLEDGMENTS}

The authors thank occupational therapy students from the Escola Superior de Saúde do Instituto Politécnico do Porto (Daniela Fernandes, Mariana Codorniz, Tânia Ferreira) for assisting in data collection.

\section{REFERENCES}

Adam, J. L.-O., Bargary, G., Bosten, J. M., Goodbourn, Patrick, T., Hogg, R. E., \& Mollon, J. D. (2013). Genetic association suggests that SMOC1 mediates between prenatal sex hormones and digit ratio. Human Genetics, 132, 415-421. http://doi.org/10.1007/ s00439-012-1259-y

Ahmed, N., Mandel, R., \& Fain, M. J. (2007). Frailty: An emerging geriatric syndrome. The American Journal of Medicine, 120, 748753. http://doi.org/10.1016/j.amjmed.2006.10.018

Anders, S. M. V. A. N. (2007). Grip strength and digit ratios are not correlated in women. American Journal of Human Biology, 19, 437-439. http://doi.org/10.1002/ajhb

Andreasen, J., Sørensen, E. E., Gobbens, R. J. J., Lund, H., \& Aadahl, M. (2014). Danish version of the Tilburg frailty indicator -Translation, cross-cultural adaption and validity pretest by cognitive interviewing. Archives of Gerontology and Geriatrics, 59, 32-38. http://doi.org/10.1016/j.archger.2014.02.007

Austin, E. J., Manning, J. T., Mcinroy, K., \& Mathews, E. (2002). A preliminary investigation of the associations between personality, cognitive ability and digit ratio. Personality and Individual Differences, 33, 1115-1124.

Barrett-Connor, E., Goodman-Gruen, D., \& Patay, B. (1999). Endogenous sex hormones and cognitive function in older men. The Journal of Clinical Endocrinology \& Metabolism, 84, 3681-3685. http://doi.org/10.1210/jcem.84.10.6086

Baumgart, M., Snyder, H. M., Carrillo, M. C., Fazio, S., Kim, H., \& Johns, H. (2015). Summary of the evidence on modifiable risk factors for cognitive decline and dementia: A population-based perspective. Alzheimer's \& Dementia: The Journal of the Alzheimer's Association, 11, 1-9. http://doi.org/10.1016/j.jalz.2015.05.016

Burton, L. A., Guterman, E., \& Baum, G. (2013). Effect of prenatal androgen on adult personality: Greater openness with more femaletypical 2D:4D digit ratios. Current Psychology, 32, 197-202.

Coelho, T., Santos, R., Paúl, C., Gobbens, R. J. J., \& Fernandes, L. (2014). Portuguese version of the Tilburg frailty indicator: Transcultural adaptation and psychometric validation. Geriatric Gerontology International, 1-10. http://doi.org/10.1111/ggi.12373.

Coolican, J., \& Peters, M. (2003). Sexual dimorphism in the 2D/4D ratio and its relation to mental rotation performance. Evolution \& Human Behavior, 24, 179-183. http://doi.org/10.1016/S1090-5138(03)00010-2.

Ellison, P. T., Bribiescas, R. G., Bentley, G. R., Campbell, B. C., Lipson, S. F., Panter-Brick, C., \& Hill, K. (2002). Population variation in age-related decline in male salivary testosterone. Human Reproduction (Oxford, England), 17, 3251-3253. http://doi.org/ 10.1093/humrep/17.12.3251 
Feldman, H. A., Longcope, C., Derby, C. A., Johannes, C. B., Araujo, A. B., Coviello, A. D., ... McKinlay, J. B. (2002). Age trends in the level of serum testosterone and other hormones in middle-aged men: Longitudinal results from the Massachusetts Male Aging Study. Journal of Clinical Endocrinology \& Metabolism, 87, 589-598. http://doi.org/10.1210/jc.87.2.589

Fink, B., Manning, J. T., \& Neave, N. (2006). The 2nd-4th digit ratio (2D:4D) and neck circumference: Implications for risk factors in coronary heart disease. International Journal of Obesity, 30, 711714. http://doi.org/10.1038/sj.ijo.0803154

Fink, B., Thanzami, V., Seydel, H., \& Manning, J. (2006). Digit ratio and hand-grip strength in German and Mizos Men: Cross-cultural evidence for an organizing effect of prenatal testosterone on strength. American Journal of Human Biology, 18, 776-782. http://doi.org/10.1002/ajhb

Folstein, M. F., Folstein, S. E., \& McHugh, P. R. (1975). "Mini-Mental State". A practical method for grading the cognitive state of patients for the clinician. Journal of Psychiatric Research, 12, 189-198.

Fried, L. P., Tangen, C. M., Walston, J., Newman, A. B., Hirsch, C., Gottdiener, J., ... Burke, G. (2001). Frailty in older adults: Evidence for a phenotype. Journal of Gerontology: Medical Sciences, $56,146-156$.

Gobbens, R., \& Assen, M. (2014). The prediction of quality of life by physical, psychological and social components of frailty in community-dwelling older people. Quality of Life Research, 23, 2289-2300. http://doi.org/10.1007/s11136-014-0672-1

Gobbens, R., Luijkx, K., Wijnen-Sponselee, M., \& Schols, J. (2010a). In Search of an integral conceptual definition of frailty: Opinions of experts. Journal of the American Medical Directors Association, 11 (5), 338-343. http://doi.org/10.1016/j.jamda.2009.09.015

Gobbens, R. J. J., van Assen, M. A L M., Luijkx, K. G., WijnenSponselee, M. T., \& Schols, J. M G A. (2010b). The Tilburg frailty indicator: Psychometric properties. Journal of the American Medical Directors Association, 11, 344-355. http://doi.org/10. 1016/j.jamda.2009.11.003

Guerrero-Berroa, E., Luo, X., Schmeidler, J., Rapp, M. A., Dahlman, K., Grossman, H. T., ... Beeri, M. S. (2009). The MMSE orientation for time domain is a strong predictor of subsequent cognitive decline in the elderly. International Journal of Geriatric Psychiatry, 24, 1429-1437.

Halil, M., Gurel, E. I., Kuyumcu, M. E., Karaismailoglu, S., Yesil, Y., Ozturk, Z. A., ... Arıgul, S. (2013). Digit (2D:4D) ratio is associated with muscle mass (MM) and strength (MS) in older adults: Possible effect of in utero androgen exposure. Archives of Gerontology and Geriatrics, 56, 358-363. http://doi.org/10.1016/ j.archger.2012.11.003

Huang, G., Wharton, W., Bhasin, S., Harman, S. M., Pencina, K. M., Tsitouras, P., ... Basaria, S. (2016). Effects of long-term testosterone administration on cognition in older men with low or low-to-normal testosterone concentrations: A prespecified secondary analysis of data from the randomised, double-blind, placebo-controlled TEAAM trial. The Lancet Diabetes \& Endocrinology, 4, 657-665. http://doi.org/10.1016/S2213-8587 (16)30102-4

Lahousse, L., Maes, B., Ziere, G., \& Loth, D. W. (2014). Adverse outcomes of frailty in the elderly: The Rotterdam Study. Euro- pean Journal of Epidemiology, 419-427. http://doi.org/10.1007/ s10654-014-9924-1

Lawson, R. A., Yarnall, A. J., Duncan, G. W., Breen, D. P., Khoo, T. K., Williams-Gray, C. H. ..., .. Brody (1969). Assessment of older people: Self-maintaining and instrumental activities of daily living. The Gerontologist, 9(3 Part 1), 179-186.

Lippa, R. (2006). Finger lengths, 2D:4D ratios, and their relation to gender-related personality traits and the Big Five. Biological Psychology, 71, 116-121.

Mahoney, F. I., \& Barthel, D. W. (1965). Functional evaluation: The Barthel Index. Maryland State Medical Journal, 14, 56-61.

Malas, M. A., Dogan, S., Hilal Evcil, E., \& Desdicioglu, K. (2006). Fetal development of the hand, digits and digit ratio (2D:4D). Early Human Development, 82, 469-475. http://doi.org/10.1016/j. earlhumdev.2005.12.002

Manning, J. T., Scutt, D., Wilson, J., \& Lewis-Jones, D. I. (1998). The ratio of 2 nd to 4 th digit length: A predictor of sperm numbers and concentrations of testosterone, luteinizing hormone and oestrogen. Human Reproduction (Oxford, England), 13, 30003004. http://doi.org/10.1093/humrep/13.11.3000

McIntyre, M. H., Cohn, B. A., \& Ellison, P. T. (2006). Sex dimorphism in digital formulae of children. American Journal of Physical Anthropology, 129, 143-150. http://doi.org/10.1002/ajpa.20240

Moffat, S. D. (2005). Effects of testosterone on cognitive and brain aging in elderly men. Annals of the New York Academy of Sciences, 1055, 80-92. http://doi.org/10.1196/annals.1323.014

Moffat, S., Zonderman, A., Metter, E., Blackman, M., Harman, S., \& Resnick, S. (2002). Longitudinal assessment of serum free testosterone concentration predicts memory performance and cognitive status in elderly men. The Journal of Clinical Endocrinology and Metabolism, 87, 5001-5007. http://doi.org/10.1210/jc.2002-020419

Neave, N., Laing, S., Fink, B., \& Manning, J. T. (2003). Second to fourth digit ratio, testosterone and perceived male dominance. Proceedings of the Royal Society B, 270, 2167-2172. http://doi. org/10.1098/rspb.2003.2502

Poulin, M., O'Connell, R. L., \& Freeman, L. M. (2004). Picture recall skills correlate with $2 \mathrm{D}: 4 \mathrm{D}$ ratio in women but not men. Evolution \& Human Behavior, 25, 174-181. http://doi.org/10. 1016/j.evolhumbehav.2004.03.004

Ribeiro, E., Neave, N., Morais, R. N., \& Manning, J. T. (2016). Direct versus indirect measurement of digit ratio (2D:4D): A critical review of the literature and new data. Evolutionary Psychology, 1-8.

Sakuma, K., \& Yamaguchi, A. (2012). Sarcopenia and age-related endocrine function. International Journal of Endocrinology, 2012, 1-10. http://doi.org/10.1155/2012/127362

Santos-Eggimann, B., Cuénoud, P., Spagnoli, J., \& Junod, J. (2009). Prevalence of frailty in middle-aged and older community-dwelling europeans living in 10 countries. Journal of Gerontology: Medical Sciences, 64, 675-681. http://doi.org/10.1093/gerona/glp012

Srinivas-Shankar, U., \& Wu, F. C. W. (2009). Frailty and muscle function: Role for testosterone? Frontiers of Hormone Research, 37, 133-149. http://doi.org/10.1159/000176050

Voracek, M., Tran, U. S., \& Dressler, S. G. (2010). Digit ratio (2D: 4D) and sensation seeking: New data and meta-analysis. Personality and Individual Differences, 48, 72-77. doi:10.1016/j. paid.2009.08.019 
Wahjoepramono, E. J., Asih, P. R., Aniwiyanti, V., Taddei, K., Dhaliwal, S., Fuller, S., ... Martins, R. (2016). The effects of testosterone supplementation on cognitive functioning in older men. CNS a Neurological Disorders: Drug Targets, 15, 337-343. http://www.benthamdirect.org/pages/all_b_bypublication.phplnhttp:// ovidsp.ovid.com/ovidweb.cgi? $\mathrm{T}=\mathrm{JS} \& \mathrm{PAGE}=$ reference $\& \mathrm{D}=$ emed 13 $\& N E W S=N \& A N=20160249438$

Yeap, B. B. (2009). Are declining testosterone levels a major risk factor for ill-health in aging men? International Journal of Impotence Research, 21, 24-36. http://doi.org/10.1038/ijir.2008.60

Yeap, B. B., Almeida, O. P., Hyde, Z., Chubb, S. A. P., Hankey, G. J., Jamrozik, K., \& Flicker, L. (2008). Higher serum free testosterone is associated with better cognitive function in older men, while total testosterone is not. The Health in Men Study. Clinical Endocrinology, 68, 404-412. http://doi.org/10.1111/j.1365-2265.2007.03055.x

How to cite this article: Gonçalves C, Coelho T, Machado S, Rocha NB. 2D:4D digit ratio is associated with cognitive decline but not frailty in communitydwelling older adults. Am J Hum Biol. 2017;00: e23003. https://doi.org/10.1002/ajhb.23003 